\title{
Evaluation of the efficacy, safety, and acceptability of an eyelid warming device for the treatment of meibomian gland dysfunction
}

This article was published in the following Dove Press journal:

Clinical Ophthalmology

6 October 2014

Number of times this article has been viewed

\author{
José Manuel Benitez del \\ Castillo' \\ Thomas Kaercher ${ }^{2}$ \\ Khaled Mansour ${ }^{3}$ \\ Edward Wylegala ${ }^{4}$ \\ Harminder Dua ${ }^{5}$ \\ 'Universidad Complutense, \\ Madrid, Spain; ${ }^{2}$ Augenarztpraxis, \\ Heidelberg, Germany; ${ }^{3}$ Department \\ of Ophthalmology, Tjongerschans \\ Hospital, Heerenveen, the \\ Netherlands; ${ }^{4}$ Department of \\ Ophthalmology, Medical University \\ of Silesia, District Railway Hospital, \\ Katowice, Poland; ${ }^{5}$ Division of \\ Ophthalmology and Visual Sciences, \\ Eye ENT Centre, Queens Medical \\ Centre, Nottingham, UK
}

\begin{abstract}
Meibomian gland dysfunction (MGD) is widespread and has significant impact on patients' quality of life. Eyelid hygiene is the mainstay of treatment but is unstandardized and requires commitment from the patient and encouragement from the ophthalmologist. Blephasteam ${ }^{\circledR}$ is an eyelid warming device designed to be an easy-to-use and standardized treatment for MGD. In the present study, 73 patients were treated for 21 days with twice daily Blephasteam ${ }^{\circledR}$ sessions. The primary efficacy variable, a symptomatology visual analog scale score, declined from $63.07 \pm 21.23$ (mean \pm standard deviation) on day 0 to $41.90 \pm 25.49$ on day 21 . There were also improvements in a number of secondary efficacy variables including subjective ocular symptoms and clinical signs and symptoms of MGD and dry eye, though tear film breakup time and tear osmolarity were not improved. Global efficacy was assessed as satisfactory or very satisfactory in $83.8 \%$ of cases. Patient-reported subjective ocular symptoms declined during the study, and a majority of patients rated the efficacy of Blephasteam ${ }^{\circledR}$ as satisfactory or very satisfactory. Most patients found the device comfortable and were able to continue with normal activities (reading, watching TV, using a computer) during the Blephasteam ${ }^{\circledR}$ session. No safety or tolerability issues were identified.
\end{abstract}

Keywords: dry eye, Blephasteam ${ }^{\mathbb{B}}$

\section{Introduction}

Meibomian gland dysfunction (MGD) is a chronic, diffuse abnormality of the meibomian glands and a major cause of dry eye disease. ${ }^{1}$ The prevalence of MGD varies widely, ranging from $3.5 \%$ to $19.9 \%$ in Caucasians to more than $60 \%$ in Asian populations. ${ }^{1}$

MGD is commonly characterized by terminal duct obstruction and/or qualitative/ quantitative changes in the glandular secretion. ${ }^{2}$ Ocular symptoms include irritation, itching, stinging, light sensitivity, blurred vision, and glued eyelids on waking. Due to the chronic nature of this disorder, symptoms can impact on a patient's quality of life. . $^{3,4}$

Eyelid hygiene is the mainstay of treatment for $\mathrm{MGD},{ }^{5}$ the aim being to warm the eyelids to $40^{\circ} \mathrm{C}$ to melt the meibum, aiding its clearance through massage or the application of pressure. Eyelid-warming devices have been developed to provide an easy-to-use and standardized approach to treatment. Improvements in tear film lipid layer thickness and ocular comfort in normal subjects and patients with dry-eye disease have been observed with a novel eyelid-warming device (Blephasteam ${ }^{\circledR}$; Laboratoires Thea, Clermont-Ferrand, France). ${ }^{6-9}$ A recent study also showed that the device increases ocular temperature sufficiently to melt meibum. ${ }^{10}$ The device
Correspondence: José Manuel Benítez de Castillo

Ocular Surface and Inflammation, Department Ophthalmology, Hospital Clinico San Carlos, Madrid 28040, Spain Tel +34913303963

Fax +34913303975

Email josemanuel.benitez@salud.madrid.org 
also appears to be superior to moist, warm compresses in providing a consistent warm ocular environment and in improving symptoms. ${ }^{11}$

The aim of this study, Evaluation of Satisfaction Regarding Patient's Management of Ocular Surface Diseases, ESPOIR International, was to investigate the efficacy and safety of the Blephasteam ${ }^{\circledR}$ eyelid-warming device in the management of patients with MGD in Europe.

\section{Methods}

ESPOIR International was a prospective, open-label, uncontrolled, Phase IV study, which took place in Belgium, Germany, the Netherlands, Poland, Spain, Switzerland, and the UK between December 2009 and January 2011. The objective of the study was to evaluate the efficacy of the Blephasteam ${ }^{\circledR}$ eyelid-warming device to treat the symptoms of MGD, and the acceptability of using the Blephasteam ${ }^{\circledR}$ device by patients who were guided by ophthalmologists, and to obtain information on treatment patterns and management of patients with symptomatic MGD and/or dry eye related to MGD. The study was conducted in accordance with Good Clinical Practice guidelines (ICH Guidelines and European directive 2001/20/CE) and the Declaration of Helsinki (2004). ${ }^{12}$

\section{Inclusion and exclusion criteria}

Patients with symptomatic MGD and/or dry eye related to MGD which had been stable for at least 1 month were eligible for inclusion in the study. Patients having any of the following items in either eye were excluded: active pathology requiring a change in ocular treatment within the previous month; history of surgical events, including refractive surgery, within the last 6 months; any ocular anomaly interfering with the ocular surface; best far corrected visual acuity (VA) $\leq 1 / 10$; history of trauma or infection within the previous 3 months; clinically relevant flare on presentation. Patients with any medical or surgical history, disorder, or disease judged by the investigator to be incompatible with the study, or who had a known hypersensitivity to a component of the test products, or who had participated in another clinical study within the last 3 months were also excluded.

\section{Study treatment}

Blephasteam $^{\circledR}$ is a medical device consisting of a pair of goggles designed to relieve the symptoms of MGD (Figure 1). The eyepieces of the goggles create a warm moist chamber that promotes fluidization of the secretions in the glands, facilitating removal through massage and the application

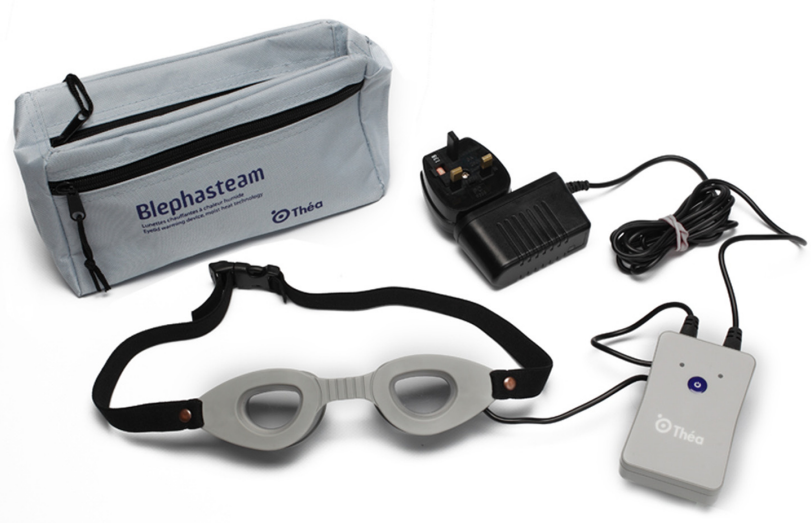

Figure I The Blephasteam ${ }^{\circledR}$ eyelid-warming device. Note: Blephasteam ${ }^{\circledR}$; Laboratoires Thea, Clermont-Ferrand, France.

of pressure on the lower eyelids. The alternate currentsupplied device was plugged in for 15 minutes, and lights indicated when it was ready for use. Two disposable rings moistened with drinking water were inserted into each eyepiece, and the goggles were worn for 10 minutes, which was timed by the device. Patients were treated with Blephasteam ${ }^{\circledR}$ twice daily for 21 days, allowing at least 4 hours between each session.

Contact lenses had to be removed while using the Blephasteam $^{\circledR}$ device. The use of tear substitutes was permitted during the study, but they were not allowed to be instilled for at least 15 minutes before or after use of the Blephasteam ${ }^{\circledR}$ device.

No specific measures were taken to ensure compliance with the study regimes.

\section{Efficacy parameters}

Patients attended the center at inclusion (visit one; day 0 ) and at the end of the study, which took place at 21 days \pm 2 days (visit two; day 21). Details of patients' ocular medical history and treatment were recorded on entry into the study. Treatment with Blephasteam ${ }^{\circledR}$ terminated the day before the end-of-study visit.

Patients also completed a diary on days $0,2,4,6,12$, and 20 and recorded the following details: global assessment of severity of ocular symptoms within the last 48 hours on waking, comfort during Blephasteam ${ }^{\circledR}$ use, and global efficacy assessment.

\section{Primary efficacy variable}

The primary efficacy parameter was evaluation of ocular symptoms for both eyes together within the last 48 hours using a visual analog scale on day 0 and day 21 . Patients were asked to mark a vertical line on a horizontal line, indicating 
the level of ocular discomfort. The scale ranged from $0 \mathrm{~mm}=$ no discomfort to $100 \mathrm{~mm}=$ maximal discomfort .

\section{Secondary efficacy variables}

\section{Global assessment of symptomatology}

Patients also evaluated their ocular symptom severity within the last 48 hours using a 0 to 4 scale on days 0 (before use of device), 2, 4, 6, 12, and 20.

\section{Global assessment of ocular symptoms}

The severity of the following ocular symptoms for both eyes within the last 48 hours was assessed by the ophthalmologist at clinic visits on days 0 and 21: burning and stinging sensation, sensitivity to light, watering, visual fatigue, grittiness, and erythematous and inflamed eyelids. Patients rated symptoms on the following severity scale: $0=$ none, $1=$ present but not disturbing, $2=$ disturbing, $3=$ very disturbing (maximum score 18).

The severity of ocular symptoms on awaking was assessed via patient diaries on days 0 (before use of device), $4,6,12$, and 20. Ocular symptoms included eyes scratched and burnt, painful eyes/sensitivity to light, watery eyes, visual fatigue/unclear vision, sandy sensation, red and irritated eyelids, crusts and secretions. Patients rated symptoms on the following severity scale: $0=$ none, $1=$ present but not disturbing, $2=$ disturbing, $3=$ very disturbing.

\section{Comfort during Blephasteam ${ }^{\circledR}$ use}

Comfort during Blephasteam ${ }^{\circledR}$ use was assessed by asking patients the following questions on days 2, 4, 6, 12, and 20: Did you keep your eyes closed? Yes (1) or no (0); Were you able to read? Yes (1) or no (0); Were you able to watch TV? Yes (1) or no (0); Were you able to use a computer? Yes (1) or no (0).

\section{Slit lamp examination}

Each eye was examined separately using a slit lamp on days 0 and 21 for conjunctival hyperemia and scored from 1 (normal) to 6 (very severe) points using the ordinal McMonnies photographic scale..$^{13}$

Chemosis, watering, conjunctival discharge, palpebral edema, folliculopapillary conjunctivitis, anterior chamber flare, and other abnormalities, were scored on a 4-point ordinal score.

\section{Lid margin examination}

The quality of the meibum and severity of lid scales or crusts, lid redness, lid swelling, and meibomian gland plugging were assessed on days 0 (before use of device) and day 21 .
The quality of the meibum was scored according to the following 5-point scale: $0=$ fluid and clear aspect (normal sebum), $1=$ turbid, $2=$ granular, $3=$ pasty, $4=$ complete meibomian block. The severity of lid scales or crusts, lid redness, lid swelling, and meibomian gland plugging were graded from 0 to 4 : $0=$ none, $1=$ mild, $2=$ moderate, $3=$ severe, $4=$ very severe. A total meibomitis score was obtained for each eye ranging from 0 to 20 .

\section{Fluorescein test including tear breakup time}

Each eye was examined separately after the application of Fluo Plus ${ }^{\circledR}$ (Gecis sarl, Neung sur Beuvron, France) and rated on a 4-point ordinal scale. Breakup time (BUT) was measured three times for each eye separately, and the mean of the three measurements was the value analyzed.

\section{Lissamine green test}

Assessment of punctation by means of lissamine green staining was performed in each eye, in each of the three parts of the corneoconjunctival exposed surface, on days 0 and 21, making use of a 4-point ordinal scale. The analysis was based on the sum of the scores for the three parts.

\section{Tear film osmolarity}

Tear film osmolarity was determined in each eye using a TearLab $^{\text {TM }}$ (TearLab Inc, San Diego, USA) device.

\section{Schirmer test}

The Schirmer test was conducted in each eye separately without anesthetic.

\section{Global efficacy assessment by the patient}

Patients answered the following questions in their diaries during and after Blephasteam ${ }^{\circledR}$ use on day 20: "On the whole, were you satisfied with the comfort provided by Blephasteam ${ }^{\circledR}$ goggles during/after your sessions?"; "On the whole, were you satisfied with this treatment?" The responses were rated as follows: $0=$ very satisfied, $1=$ satisfied, $2=$ no opinion, $3=$ rather dissatisfied, $4=$ very dissatisfied.

\section{Safety parameters}

Best far corrected VA was measured for both eyes separately using a Snellen chart on days 0 and 21 .

Investigators were asked the following question on day 21: "After 21 days of use, how do you consider the safety of the eyelid warming device $\left(\right.$ Blephasteam $\left.{ }^{\circledR}\right)$ ?" Responses were measured on a scale of 0 to 3 , where $0=$ very satisfactory, $1=$ satisfactory, $2=$ unsatisfactory, $3=$ very unsatisfactory. 
Investigators were asked the following question was measured on day 1 before and after application of Blephasteam ${ }^{\circledR}$ and on day 21.

All adverse events occurring during the study were recorded, and the relationship to the Blephasteam ${ }^{\circledR}$ device and severity were determined by the investigator.

\section{Statistical analysis}

The data were evaluated using the intention-to-treat population, comprising all patients enrolled in the study for whom there was evidence that they used the Blephasteam ${ }^{\circledR}$ device and for whom any follow-up information was available.

For the data recorded in both eyes, the analysis was performed separately for the worst eye and the other eye. The worst eye was defined as the eligible eye with the highest total score for the lid margin examination on day 0 (sum of score from five examinations). If both eyes had the same total score, the right eye was selected.

Descriptive statistics were used for the quantitative variables and frequency distribution for the categorical variables. Normality was tested using the Shapiro-Wilk test. Where the data departed significantly from normality $(P<0.05)$, comparisons between day 0 and day 21 were made using the Wilcoxon signed-rank test; otherwise, groups were compared using the paired $t$-test. The statistical analyses were performed using SAS software for Windows, version 9.2 (SAS Institute, Cary, NC, USA), and statistical tests were performed two-sided at the 5\% significance level.

Not all study centers were equipped to perform all the tests; for this reason, the number of patients assessed for some parameters was lower than planned.

\section{Results}

A total of 73 patients ( $28 \%$ male; $72 \%$ female) with a mean age of $55.3 \pm 17.3$ years were eligible for inclusion in this European study. The mean time since MGD diagnosis was 26.2 \pm 44.1 months. For patients with available data, MGD was the primary diagnosis for 49 patients and a secondary diagnosis for 19 patients. Six percent of the patients were contact lens wearers.

\section{Primary efficacy variable}

The symptomatology visual analog scale score declined from $63.07 \pm 21.23$ (mean \pm standard deviation) on day 0 to $41.90 \pm 25.49$ on day 21 ( $\mathrm{n}=70$ and 69 , respectively; intentionto-treat sample). The decrease from baseline $(22.47 \pm 23.47)$ was statistically significant $(P<0.001$, paired Student's $t$-test) (Figure 2).

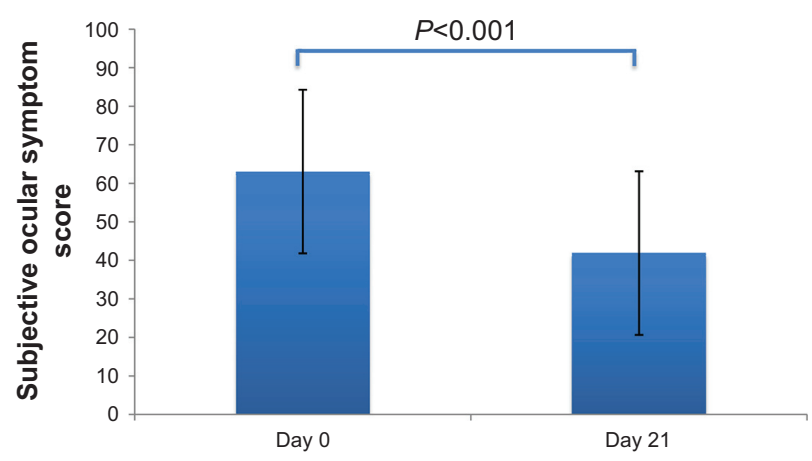

Figure 2 Symptomatology score on 0-100 VAS recorded by the investigator at day 0 and day 21 (primary efficacy variable).

Note: Columns show mean and standard deviation values of 67 and 66 patients, respectively.

Abbreviation: VAS, visual analog scale.

\section{Secondary efficacy variables: investigator-conducted assessments} Subjective ocular symptoms

Overall subjective ocular symptom score, as assessed by the investigating ophthalmologist, fell from $8.43 \pm 3.37$ at day 0 to $4.21 \pm 3.24$ by final assessment at day 21 . The reduction in ocular symptoms $(3.95 \pm 3.2)$ was statistically significant (paired Student's $t$-test). Figure 3 shows the increase in the proportion of patients free from symptoms between day 0 and day 21 in the individual symptoms.

\section{Slit lamp examination}

Bulbar conjunctival hyperemia improved between day 0 and day 21. The proportion of patients with the lowest score (corresponding to normal) increased from $5.5 \%$ on day 0 to $35.3 \%$ on day 21 (Figure 4), and there was a corresponding decrease in the number of patients with the highest scores (percentage of patients with scores of 4 or 5 decreased from $23.2 \%$ to $5.9 \%$ [with $0 \%$ for the highest score, 5] between day 0 and day 21). Slit lamp total scores fell significantly $3.94 \pm 2.75$ to $1.78 \pm 1.72$ in the worse eye, with corresponding changes in the contralateral eye $(P<0.001$, Wilcoxon signed-rank test).

\section{Lid margin examination}

The evolution in the quality of meibum and the individual signs at lid margin examination are evident in Figures 5 and 6, which illustrate the trend from high scores to low scores between days 0 and 21. For example, the proportion of patients with fluid and clear meibum increased from $1.4 \%$ before use of Blephasteam ${ }^{\circledR}$ to $11.8 \%$ at day 21 . Conversely, the proportion of patients with complete Meibomian block fell from 19.2\% before application of Blephasteam ${ }^{\circledR}$ to $2.9 \%$ by day 21 . 


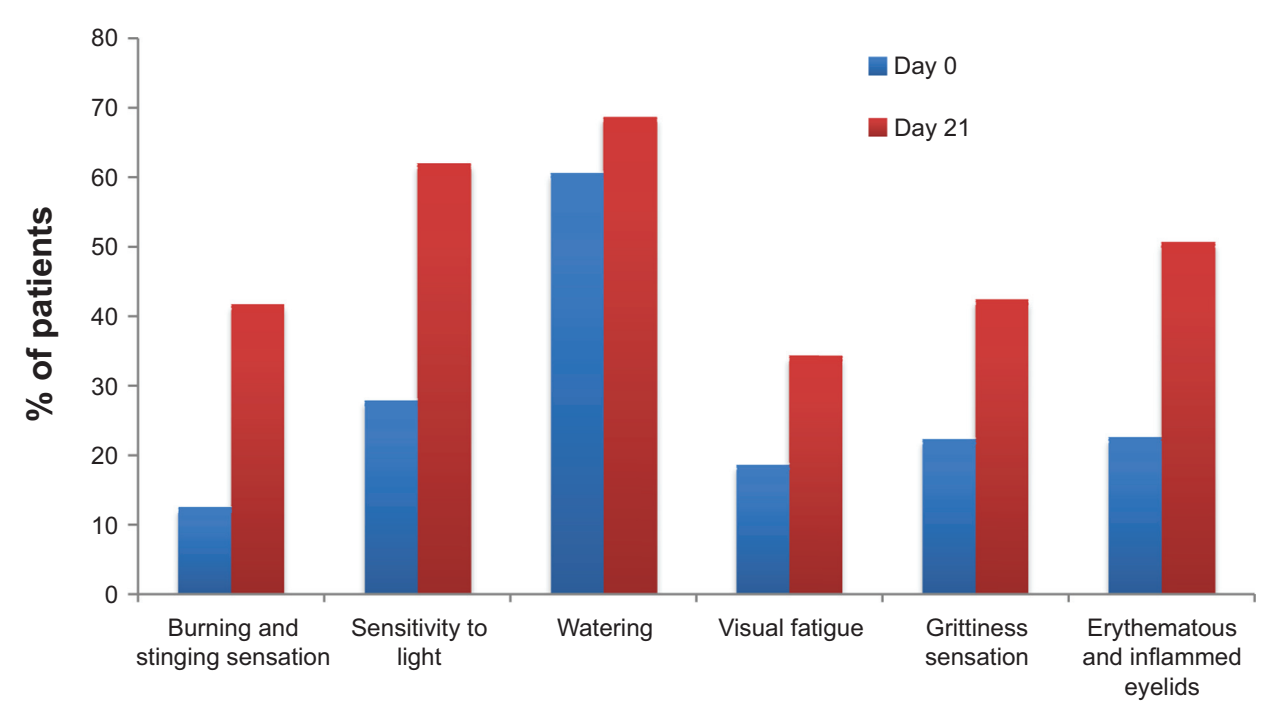

Figure 3 Proportion of patients without ocular symptoms within the last 48 hours on days 0 and 21 .

Improvements were also observed in punctate epithelial keratitis scores; the proportion of patients with a punctate keratitis assessment of "absent" increased from $43.1 \%$ at day 0 to $60.7 \%$ at day 21 , and the proportion rated as moderate or severe fell from $20.8 \%$ at day 0 to $5.5 \%$ at day 21 (all data refer to the worse eye; similar changes were seen in the contralateral eye).

\section{Tear film BUT}

Tear film BUT was assessed in a subset of patients (18 patients at both day 0 and day 21). There was a modest but statistically nonsignificant increase in BUT between day 0 and day 21 (from $6.09 \pm 3.64$ to $7.84 \pm 3.88$ in the worse eye; changes were similar in the contralateral eye).

\section{Lissamine green}

Lissamine green staining scores were assessed in 58 and 54 patients on day 0 and day 21 , respectively, and fell from

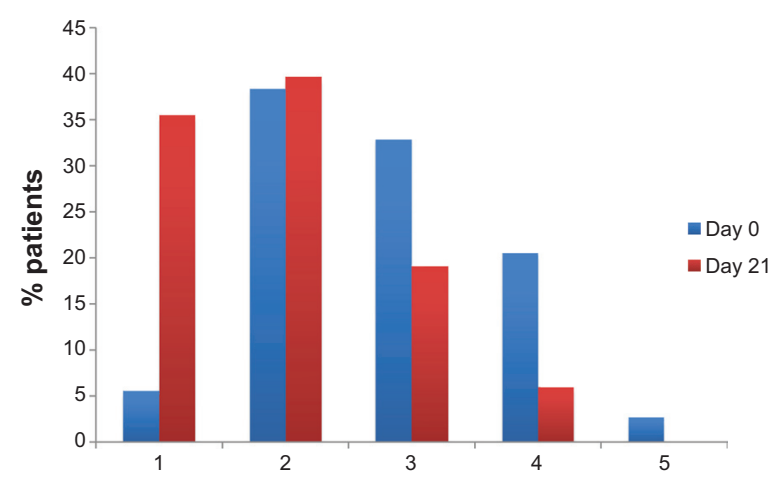

Figure 4 Bulbar conjunctival hyperemia in worse eye examined using a slit lamp. Note: Scored from I (normal) to 5 (severe) using a modified ordinal McMonnies photographic scale ${ }^{13}$ on days 0 and 21 .
$2.7 \pm 1.97$ to $1.48 \pm 1.55$. Similar changes were seen in the contralateral eye.

\section{Tear osmolarity}

Tear film osmolarity fell directly after administration of Blephasteam ${ }^{\circledR}$ on day 0 , though not statistically significantly (from $317.6 \pm 27.31$ to $305.2 \pm 12.7 \mathrm{mOsm} / \mathrm{L}$ in the worse eye and from $318.9 \pm 19.7$ to $302.8 \pm 16.87 \mathrm{mOsm} / \mathrm{L}$ in the contralateral eye). In the worse eye, but not the contralateral eye, osmolarity remained at its slightly reduced level until day 21 ( $305 \pm 10.28$ and $311 \pm 13.8 \mathrm{mOsm} / \mathrm{L}$, respectively). Osmolarity was assessed only in a limited number of patients.

\section{Schirmer test}

Schirmer test in both worse and contralateral eye showed no significant changes between day 0 and day 21 .

\section{Global efficacy}

Global efficacy, assessed by the investigator, was considered satisfactory or very satisfactory in $83.8 \%$ of cases. Global efficacy was considered unsatisfactory or very unsatisfactory in only $14.7 \%$ and $1.5 \%$ of cases, respectively (Figure 7 ).

\section{Patient-assessed parameters Global efficacy assessment by the patients}

The majority of patients rated the efficacy of Blephasteam ${ }^{\circledR}$ as satisfactory or very satisfactory, both during and after the Blephasteam $^{\circledR}$ session (Figure 8).

\section{Subjective ocular symptoms}

Subjective ocular symptoms when getting up in the morning/ before the Blephasteam ${ }^{\circledR}$ session showed a clear tendency 


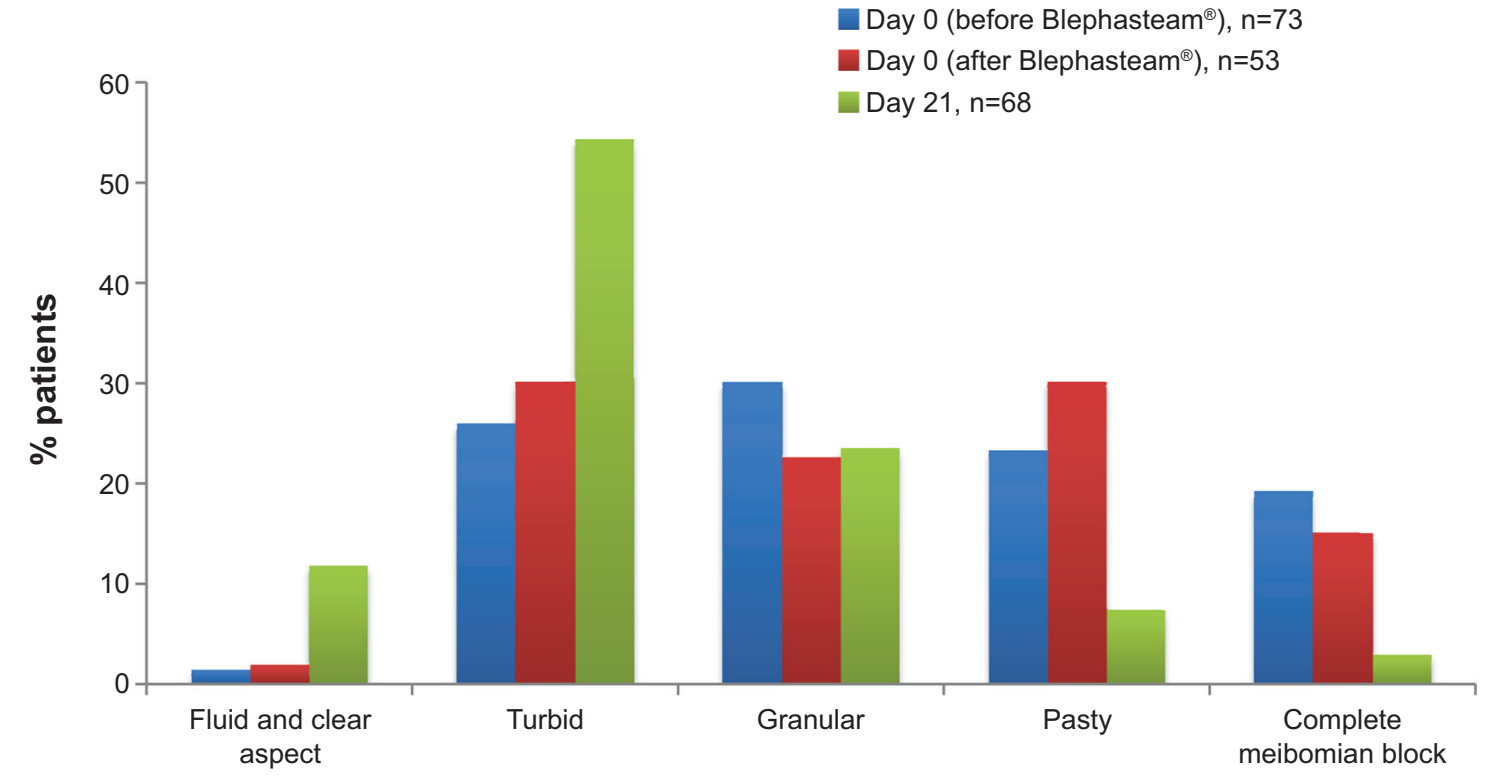

Figure 5 Quality of meibum in the worse eye on days 0 and 21 .

Note: Blephasteam ${ }^{\circledast}$; Laboratoires Thea, Clermont-Ferrand, France.
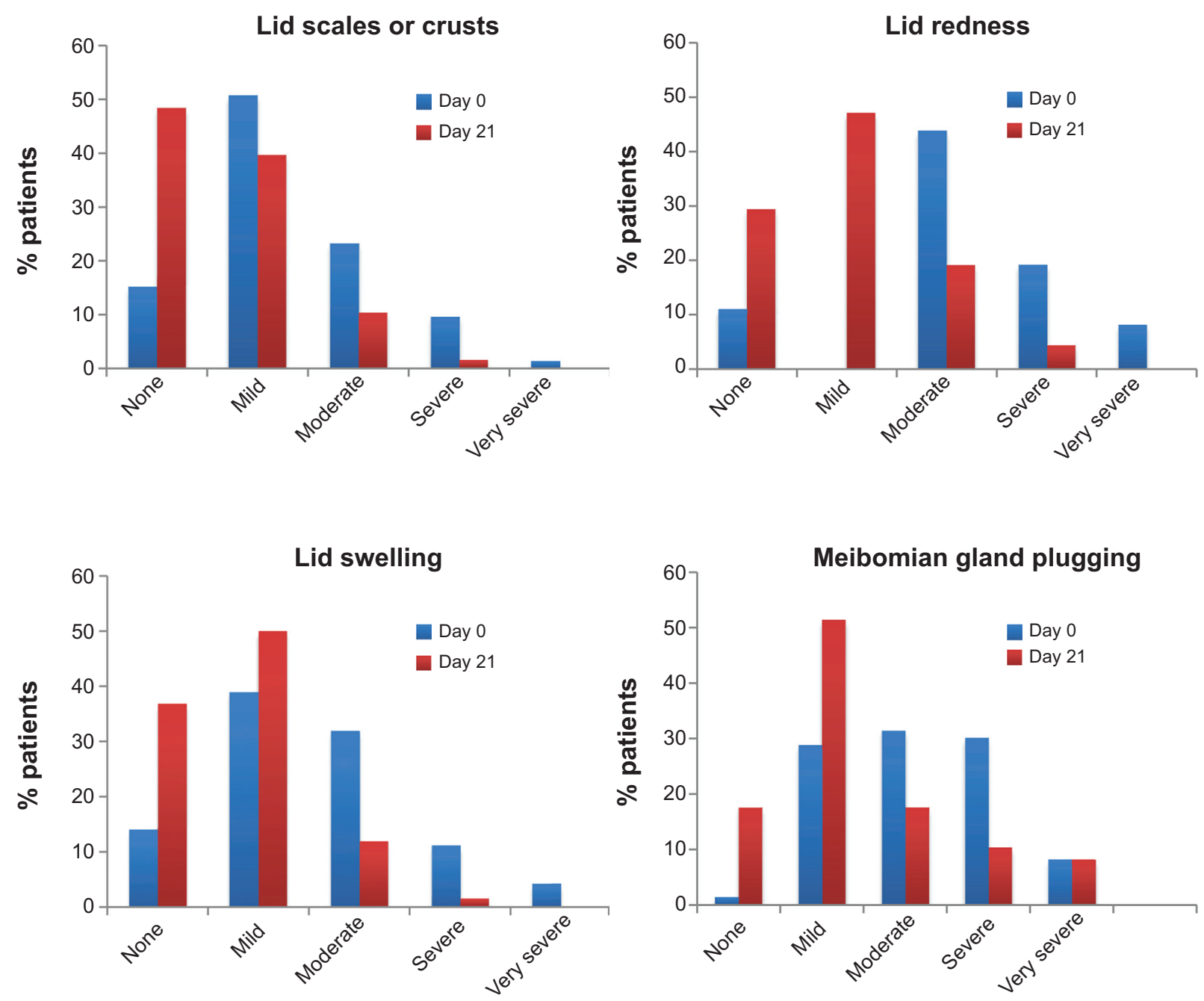

Figure 6 Lid margin examination and individual symptoms in the worse eye at day 0 and day $2 I$ ( $n=73$ and $n=68$, respectively). 


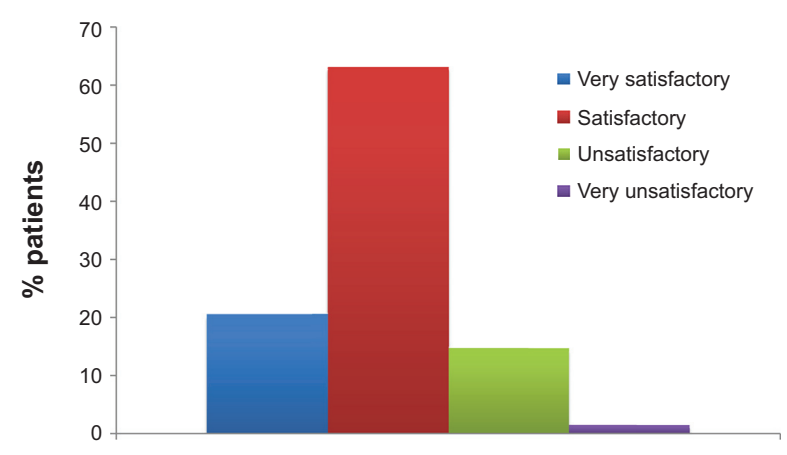

Figure 7 Global efficacy assessment by the investigator $(n=68)$.

to diminish over the course of the study. The proportion of patients without disturbing symptoms increased from day 0 to day 20 (Figure 9).

\section{Comfort during the session}

Most patients found the Blephasteam ${ }^{\circledR}$ session comfortable and could engage in other activities at days 2 and 4; the majority of patients kept their eyes open. Reading was reported as possible by $40 \%$ of patients at the start of the study, a proportion that increased to $59 \%$ by the end. Similarly, $57 \%$ of patients could watch TV at the start of the study compared with $67 \%$ at the end, and $16.4 \%$ of patients found using a computer was possible at the beginning of the study, a proportion that more than doubled by study end $(37 \%)$.

Between days 2 and 20, there were improvements in the proportion of patients who kept their eyes open, read, watched television, and used a computer during Blephasteam ${ }^{\circledR}$ use.

\section{Safety \\ Visual acuity}

There were no changes of clinical or statistical significance in corrected VA. Acuity increased by $0.12 \pm 0.49$ in the worse eye and decreased by $0.04 \pm 1.43$ in the contralateral eye.

\section{IOP}

There were no changes of note in IOP on day 0 after application of Blephasteam ${ }^{\circledR}$ and on day 21.

\section{Global safety evaluation}

The overall evaluation of safety by the investigator was very satisfactory for $53 \%$ of the patients, satisfactory for $38 \%$ of the patients, and unsatisfactory for $9 \%$ of the patients.

\section{Adverse events}

No adverse events were reported.

\section{Discussion}

MGD is a common disorder and has an important impact on patients' quality of life. ${ }^{14}$ Encouraging long-term, perhaps life-long, use of eyelid hygiene and warm massage presents a challenge for the treating ophthalmologist. Even where the patient commits to such treatment, it remains poorly standardized. ${ }^{5}$ The introduction of eyelid-warming devices, such as Blephasteam ${ }^{\circledR}$, may provide a more consistent solution for at least part of the MGD treatment regimen, particularly in the provision of a warm, moist environment for the improvement of meibum quality. Hopefully, the need

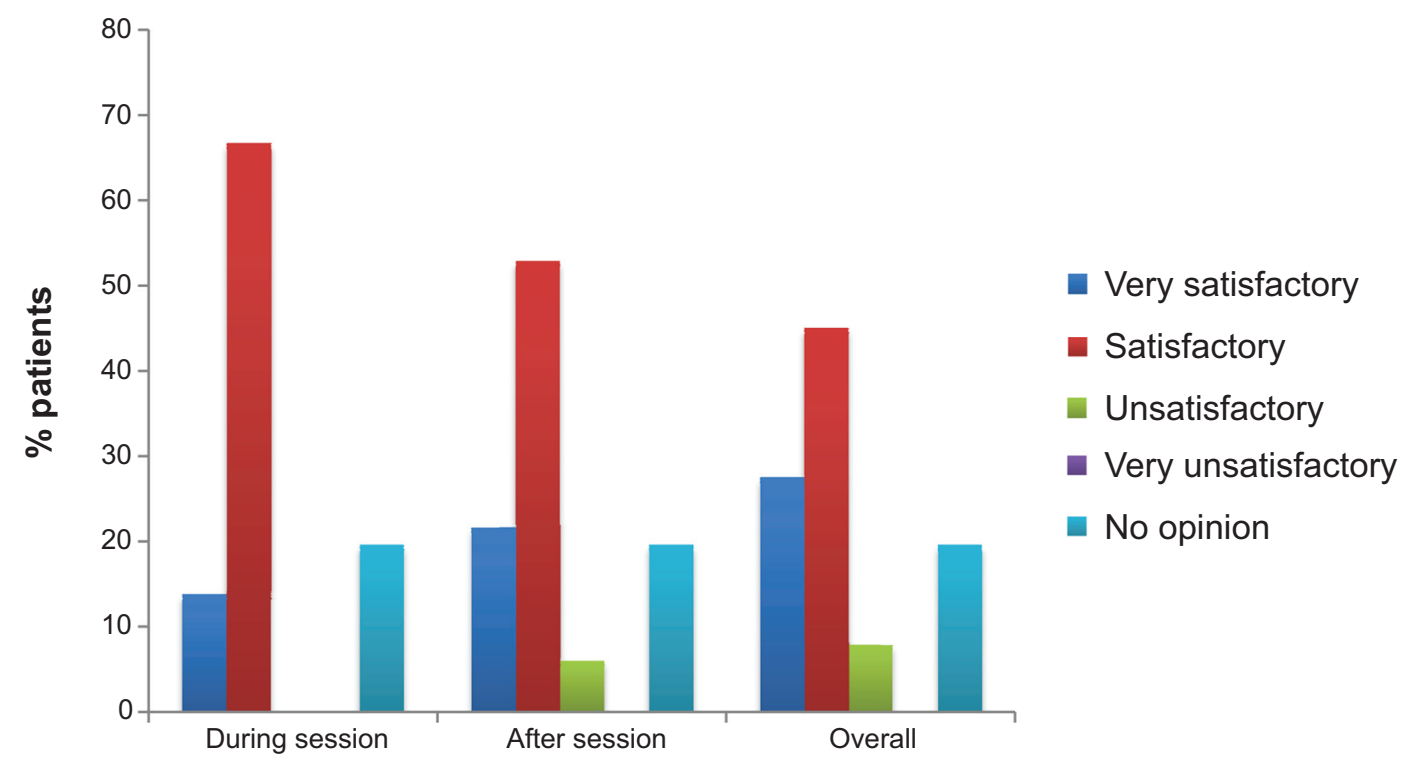

Figure 8 Global efficacy as assessed by the patient during and after Blephasteam ${ }^{\circledR}$ sessions and overall $(n=5 \mathrm{I})$. Note: Blephasteam ${ }^{\circledR}$; Laboratoires Thea, Clermont-Ferrand, France. 


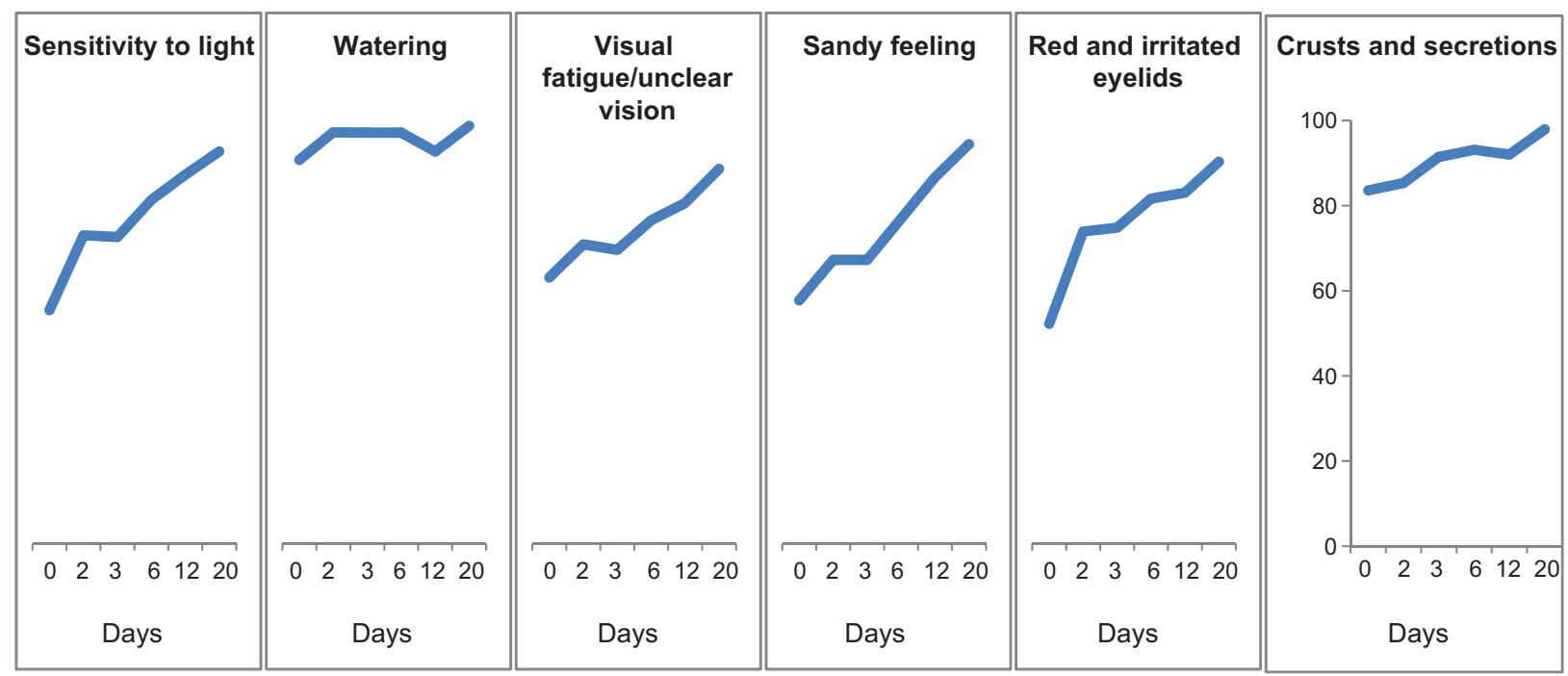

Figure 9 Subjective ocular symptoms when getting up in the morning, before the Blephasteam ${ }^{\circledR}$ session - patients with no disturbing symptoms. Note: Blephasteam ${ }^{\circledR}$; Laboratoires Thea, Clermont-Ferrand, France.

of aggressive medical treatment such as topical antibiotics and corticosteroids might not be necessary. A recent study ${ }^{15}$ of the Blephasteam ${ }^{\circledR}$ device in patients with MGD showed significant improvements in Ocular Surface Disease Index score and tear BUT. In particular, this study showed significant treatment responses in patients who had previously failed to respond to warm compress therapy.

Blephasteam ${ }^{\circledR}$ resulted in a statistically significant reduction in symptomology score after 21 days use. In addition, there were worthwhile reductions in a number of secondary efficacy parameters, including subjective ocular symptoms as well as clinical signs and symptoms of MGD. Less impressive changes in tear film BUT, osmolarity, and Schirmer test were observed, but fewer patients were assessed for these parameters. Patients appeared to be satisfied with the treatment and reported fewer ocular symptoms during treatment.

Importantly, the majority of patients found the device comfortable to use and were able to continue with activities such as watching television, reading, and using a computer, findings that could be expected to contribute towards compliance.

No safety issues were identified; ophthalmologists rated the global safety as satisfactory or very satisfactory in more than $90 \%$ of patients. IOP and VA remained unchanged, and there were no reported adverse events.

This was an open, uncontrolled naturalistic study, using a historical control; this obviously confers some disadvantages in terms of identifying efficacy. However, it offers the opportunity to examine the use of the device, its intended environment, and to identify issues associated with the device in daily usage. Moreover, it is difficult to conceive a convincing control for a device such as the Blephasteam ${ }^{\circledR}$.

Although some statistically significant differences from baseline were observed, these need to be considered in the context of the relatively small size of the study and the lack of a contemporaneous control group.

The Blephasteam ${ }^{\circledR}$ device is relatively expensive (around $€ 250$ ), particularly in comparison with generic artificial tears, and it is not generally available without cost to the patient. However, it is convenient compared with the preparation of hot compresses and provides a consistent and effective warm humidity.

Overall, the results from this preliminary international study confirm and extend those from a previous study completed in France. ${ }^{16}$ Clearly, larger, preferably controlled clinical studies are required to correctly place this device in the therapeutic armamentarium for MGD. The eyelid warming device appears to provide the consistent warm and humid environment required for improving meibum quality benefits in terms of reducing discomfort and symptoms in MGD.

\section{Disclosure}

The authors report no conflicts of interest in this work.

\section{References}

1. Nichols KK, Foulks GN, Bron AJ, et al. The international workshop on meibomian gland dysfunction: executive summary. Invest Ophthalmol Vis Sci. 2011;52(4):1922-1929.

2. Nelson JD, Shimazaki J, Benitez-del-Castillo JM, et al. The international workshop on meibomian gland dysfunction: report of the definition and classification subcommittee. Invest Ophthalmol Vis Sci. 2011; 52(4):1930-1937.

3. Pflugfelder SC. Prevalence, burden, and pharmacoeconomics of dry eye disease. Am J Manag Care. 2008;14(3 Suppl):S102-S106. 
4. Friedman NJ. Impact of dry eye disease and treatment on quality of life. Curr Opin Ophthalmol. 2010;21(4):310-316.

5. Geerling G, Tauber J, Baudouin C, et al. The international workshop on meibomian gland dysfunction: report of the subcommittee on management and treatment of meibomian gland dysfunction. Invest Ophthalmol Vis Sci. 2011;52(4):2050-2064.

6. Mitra M, Menon GJ, Casini A, et al. Tear film lipid layer thickness and ocular comfort after meibomian therapy via latent heat with a novel device in normal subjects. Eye (Lond). 2005;19(6):657-660.

7. Spiteri A, Mitra M, Menon G, et al. Tear lipid layer thickness and ocular comfort with a novel device in dry eye patients with and without Sjögren's syndrome. J Fr Ophtalmol. 2007;30(4):357-364.

8. Profazio V, Versura P, Tedeschi MG, Coslovi C, Cellini M. Blephasteam ${ }^{\circledR}$ : a novel equipment to treat meibomian gland dysfunction (MGD). A clinical and laboratory study. 6th International Conference on the Tear Film and Ocular Surface: Basic Science and Clinical Relevance; September 22-25, 2010; Florence, Italy.

9. Doan S, Chiambaretta F, Gabison EE, Cochereau I, Baudoin C. Efficacy of heating wet chamber warming goggles (Blephasteam ${ }^{\circledR}$ ) in adult posterior blepharitis. Invest Opthalmol Vis Sci. 2011;52:E-Abstract 3833.

10. Purslow C. Evaluation of the ocular tolerance of a novel eyelid-warming device used for meibomian gland dysfunction. Cont Lens Anterior Eye. 2013;36(5):226-231.
11. Pult H, Riede-Pult BH, Purslow C. A comparison of an eyelid-warming device to traditional compress therapy. Optom Vis Sci. 2012;89(7): E1035-E1041.

12. World Medical Association. Declaration of Helsinki; ethical principles for medical research involving human subjects. Ferney-Voltaire: World Medical Association; 2004. Available from http://www.wma.net/ en/30publications/10policies/b3/17c.pdf. Accessed July 29, 2014.

13. McMonnies CW, Chapman-Davies A. Assessment of conjunctival hyperemia in contact lens wearers. Part I. Am J Optom Physiol Opt. 1987; 64(4):246-250.

14. Benitez-Del-Castillo JM. How to promote and preserve eyelid health. Clin Ophthalmol. 2012;6:1689-1698.

15. Villani E, Garoli E, Canton V, Pichi F, Nucci P, Ratiglia R. Evaluation of a novel eyelid-warming device in meibomian gland dysfunction unresponsive to traditional warm compress treatment: an in vivo confocal study. Int Ophthalmol. Epub 2014 Apr 22.

16. Doan S, Chiambaretta F, Baudouin C. Evaluation of an eyelid warming device (Blephasteam ${ }^{\circledR}$ ) for the management of ocular surface diseases in France. The ESPOIR Study. J Fr Ophtalmol. In press 2014.
Clinical Ophthalmology

\section{Publish your work in this journal}

Clinical Ophthalmology is an international, peer-reviewed journa covering all subspecialties within ophthalmology. Key topics include: Optometry; Visual science; Pharmacology and drug therapy in eye diseases; Basic Sciences; Primary and Secondary eye care; Patient Safety and Quality of Care Improvements. This journal is indexed on

Submit your manuscript here: http://www.dovepress.com/clinical-ophthalmology-journal

\section{Dovepress}

PubMed Central and CAS, and is the official journal of The Society of Clinical Ophthalmology (SCO). The manuscript management system is completely online and includes a very quick and fair peer-review system, which is all easy to use. Visit http://www.dovepress.com/ testimonials.php to read real quotes from published authors. 